\title{
mGluR2/3 in the Lateral Amygdala is Required for Fear Extinction: Cortical Input Synapses onto the Lateral Amygdala as a Target Site of the mGluR2/3 Action
}

\author{
Jihye Kim ${ }^{1,2}$, Bobae An ${ }^{1,2}$, Jeongyeon Kim ${ }^{1,2}$, Sewon Park', Sungmo Park', Ingie Hong', Sukwon Lee', \\ Kyungjoon Park ${ }^{*, I}$ and Sukwoo Choi*, I \\ 'School of Biological Sciences, College of Natural Sciences, Seoul National University, Seoul, Republic of Korea
}

\begin{abstract}
Various subtypes of metabotropic glutamate receptors (mGluRs) have been implicated in fear extinction, but mGluR2/3 subtype has not been tested. Here, we found that microinjection of an mGluR2/3 antagonist, LY34I495, into the lateral amygdala (LA), but not into the adjacent central amygdala (CeA), impaired extinction retention without affecting within-session extinction. In contrast, we failed to detect any significant changes in motility and anxiety during a period when extinction training or retention was performed after LY34I495 injection, suggesting that the effect of LY34I 495 is specific to conditioned responses. Subsequently, on the basis of a previous finding that a long-term potentiation of presynaptic efficacy at cortical input synapses onto the lateral amygdala (C-LA synapses) supports conditioned fear, we tested the hypothesis that activation of mGluR2/3 leads to fear extinction via a long-term weakening of presynaptic functions at C-LA synapses. Fear extinction produced a decrease in C-LA synaptic efficacy, whereas LY34I495 infusion into the LA blocked this extinction-induced C-LA efficacy decrease without altering synaptic efficacy at other LA synapses. Furthermore, extinction enhanced paired pulse ratio (PPR) of EPSCs, which inversely correlates with presynaptic release probability, whereas LY34I495 infusion into the LA attenuated the extinction-induced increase in PPR, suggesting the presence of mGluR2/3-dependent presynaptic changes after extinction. Consistently, extinction occluded a presynaptic form of depression at C-LA synapses, whereas the LY34I495 infusion into the LA rescued this occlusion. Together, our findings suggest that $m G l u R 2 / 3$ is required for extinction retention and that the mGluR2/3 action is mediated by the long-term weakening of release probability at C-LA synapses.

Neuropsychopharmacology (2015) 40, 29I6-2928; doi:10.1038/npp.2015.I45; published online 17 June 2015
\end{abstract}

\section{INTRODUCTION}

Fear extinction, an animal model of exposure therapy, has been used to develop novel drugs to enhance the effectiveness of exposure therapy (Davis et al, 2006; Myers et al, 2011). In most cases, mechanisms underlying fear extinction have been studied using auditory fear conditioning and subsequent extinction (Quirk et al, 1997; Maren, 1999; Royer and Pare, 2002; Herry et al, 2008). Different subtypes of mGluRs (mGluR1, mGluR5, and mGluR7) have been shown to be involved in fear extinction. mGluR1/5 has been shown to be involved in fear extinction via postsynaptic mechanisms at T-LA synapses (Kim et al, 2007a). mGluR5 also appears to contribute to fear extinction via postsynaptic mechanisms at synapses in the amygdala and the infralimbic prefrontal cortex (IL; Fontanez-Nuin et al, 2011; Mao et al, 2013; Sepulveda-Orengo et al, 2013; Sethna and Wang, 2014).

*Correspondence: Dr K Park and Dr S Choi, School of Biological Sciences, Seoul National University, Seoul 151-742, Republic of Korea, E-mail: park79@gmail.com and sukwool2@snu.ac.kr

${ }^{2}$ These authors contributed equally to this work.

Received 22 January 20 I 5; revised 7 May 20 I5; accepted 20 May 20I 5; accepted article preview online 25 May 2015
Thus, at LA and IL synapses, mGluR1 and mGluR5 contribute to fear extinction via postsynaptic mechanisms. In addition, mGluR7 appears to be required for fear extinction, although the molecular and cellular mechanisms underlying the mGluR7 action are currently unclear (Fendt et al, 2008; Toth et al, 2012). However, it remains to be elucidated whether mGluR2/3 is required for fear extinction and, if it is required, through which mechanisms it contributes.

Ample evidence suggests that extinction training results in the formation of extinction memory that inhibits original fear memory (Myers and Davis, 2002; Maren and Quirk, 2004; Ehrlich et al, 2009), and the extinction memory is thought to be encoded in the prefrontal cortex and amygdala intercalated neurons (Milad and Quirk, 2002; Likhtik et al, 2008; Pare and Duvarci, 2012). In addition, fear extinction also involves weakening of the original fear memory encoded in the LA: long-term potentiation of synaptic efficacy at both thalamic input synapses onto the LA (T-LA synapses) and C-LA synapses encodes conditioned fear memory (Quirk et al, 1997; Rogan et al, 1997; Tsvetkov et al, 2002; Sah and Lopez De Armentia, 2003; Schroeder and Shinnick-Gallagher, 2005), and depotentiation or long-term depression at T-LA synapses contributes to fear extinction 
(Lin et al, 2005; Kim et al, 2007b; Dalton et al, 2008; see also Hong et al, 2009; Kim et al, 2010). However, whether weakening of C-LA synaptic efficacy is responsible for fear extinction has not been rigorously tested.

The C-LA pathway has been relatively well studied through anatomical studies and in vitro slice physiology. We and others have previously characterized synaptic weakening in the C-LA pathway and underlying mechanisms in vitro (Lin et al, 2005; Hong et al, 2009). Synaptic weakening in this pathway has been shown to be dependent upon mGluR2/3. However, it is unknown whether such an in vitro plasticity mechanism, which depends upon mGluR2/3, is required for fear extinction in vivo.

In the present study, we have provided strong evidence that $\mathrm{mGluR} 2 / 3$ in the LA is required for extinction retention but not within-session extinction. Among various LA synapses, C-LA synapses appear to mediate the mGluR2/3 action, as evidenced by the selective effects of the mGluR2/3 blockade on C-LA synapses but not on other types of LA synapses.

\section{MATERIALS AND METHODS}

\section{Animals}

Male Sprague-Dawley rats $(4 \sim 5$ weeks old) were individually housed for $6 \sim 8$ days before all experiments under an inverted $12 \mathrm{~h} \mathrm{light/dark} \mathrm{cycle} \mathrm{(lights} \mathrm{off} \mathrm{at} \mathrm{09:00} \mathrm{hours)} \mathrm{and}$ were provided with food and water ad libitum. Behavioral training was performed during the dark portion of the light/ dark cycle. All behavioral procedures were approved by the Institute of Laboratory Animal Resources of Seoul National University.

\section{Surgery and Histology}

Rats were anesthetized with sodium pentobarbital $(50 \mathrm{mg} / \mathrm{kg}$, i.p.). When fully anesthetized, rats were mounted on a stereotaxic apparatus (Stoelting, Wood Dale, IL) and implanted bilaterally into the LA (AP, -2.3 to $-2.35 \mathrm{~mm}$; $\mathrm{ML}, \pm 4.85 \mathrm{~mm}$; and $\mathrm{DV},-6.7 \mathrm{~mm}$ from bregma) or the CeA (AP, $-2.3 \mathrm{~mm}$; $\mathrm{ML}, \pm 4.05 \mathrm{~mm}$; and $\mathrm{DV},-6.7 \mathrm{~mm}$ from bregma) with 26-gauge stainless steel cannulas (model C315G; Plastics One, Roanoke, VA). To prevent clogging, 32-gauge dummy cannulas were inserted into guide cannulas. Jewelry screws were implanted over the skull to serve as anchors, and the entire assembly was affixed to the skull with dental cement. Rats were given $5 \sim 7$ days to recover before the experiments. To verify the intra-LA placement of the cannula tips, the rats were anesthetized with urethane ( $1 \mathrm{~g} / \mathrm{kg}$, i.p.) following the completion of the experiments and transcardially perfused with $0.9 \%$ saline solution and $10 \%$ buffered formalin. The brains were removed and postfixed overnight. Coronal sections $(100 \mu \mathrm{m}$ thick) were obtained using a vibroslicer (NVSL, World Precision Instruments, Sarasota, FL) and stained with cresyl violet. The placement of the cannula tips was examined under a light microscope. Data were collected from rats in which the adjacent external capsule of the amygdala was intact and the thalamic fibers onto the LA from the internal capsule were minimally damaged. In the Figure $2 c$ experiment, two rats in the vehicle-infused control group and one rat in the
LY341495-infused group were excluded from further analyses because these rats showed low freezing in response to the first CS during extinction training and no freezing in response to the rest of the CSs.

\section{Intra-Amygdala Infusion}

LY341495 (Tocris Bioscience) was dissolved in 50\% DMSO/ $50 \%$ saline and adjusted to $\mathrm{pH} 7.2 \sim 7.4$ using $1 \mathrm{~N} \mathrm{NaOH}$. Forty-eight hours after fear conditioning, LY341495 (0.1 $\mu \mathrm{g}$ / $0.5 \mu \mathrm{l}$ per side) or vehicle (50\% DMSO/50\% saline) was administered bilaterally into the LA or CeA via a 33-gauge injector cannula (C315I; Plastics One) attached to a $10-\mu \mathrm{l}$ Hamilton syringe at a rate of $0.25 \mu \mathrm{l} / \mathrm{min}$. The dose of LY341495 was chosen based on previous studies (Walker et al, 2002; Chi et al, 2006). After drug infusion, the injector cannulas were left in place for an additional $1 \mathrm{~min}$ to allow the drug to diffuse away from the cannula tip. Dummy cannulas were then swapped in and the rats were returned to their home cages.

\section{Apparatus}

Fear conditioning and extinction took place in two distinct contexts (context $\mathrm{A}$ and $\mathrm{B}$ ). Context $\mathrm{A}$ was a rectangular Plexiglas box with a metal grid floor connected to an electrical current source (Coulbourn Instruments, Allentown, PA), which was set in a sound attenuating room. The chamber was illuminated with white light and was cleaned with $70 \%$ ethanol. Context B was a cylindrical Plexiglas chamber with a flat Formica floor and was cleaned with $1 \%$ acetic acid. Open field tests were performed in a cylindrical chamber with an $80 \mathrm{~cm}$ diameter and $40 \mathrm{~cm}$ wall height. The chamber was divided into the peripheral (within $20 \mathrm{~cm}$ from the walls) and central (40 cm diameter) zones. All training sessions were recorded.

\section{Fear Conditioning and Extinction}

On day 1 , fear conditioning was conducted by three pairings of a neutral tone (CS; $30 \mathrm{~s}, 2.8 \mathrm{kHz}, 85 \mathrm{~dB}$ ) and an electric foot shock (US; $0.7 \mathrm{~mA}, 1 \mathrm{~s}$ ) that co-terminated with the tone. On day 3, LY341495 or vehicle was infused into the LA or the CeA through injector cannulas $15 \mathrm{~min}$ before extinction. Fear extinction took place in the context B, in which rats were presented with 20 non-reinforced CS presentations at an average interval of $100 \mathrm{~s}$. Rats were returned to their home cage after the last tone presentation. For the retention test on day 4, one tone was presented after a 4-min acclimation to context B. Conditioned freezing was defined as immobility except for respiratory movements and was quantified by trained observers who were blind to the experimental groups. Freezing time was normalized to the duration of tone presentation. Rats that showed a freezing time of less than $20 \mathrm{~s}$ at the last pairing of the fear conditioning were regarded as a conditioning failure and were discarded from subsequent experiments.

\section{Open Field Test}

Rats that went through fear conditioning or extinction were examined in the open field for $10 \mathrm{~min}$ to test their general 
activity and anxiety level. A group of rats that underwent fear conditioning was infused with LY341495 or vehicle $48 \mathrm{~h}$ after the conditioning and examined in the open field $15 \mathrm{~min}$ after the infusion. A separate group of conditioned rats were examined in the open field $24 \mathrm{~h}$ after drug infusion and subsequent fear extinction. The rats' behavior was examined using EthoVision XT software (Noldus, Wageningen, The Netherlands).

\section{Slice Preparation}

Rats were anesthetized with isoflurane and decapitated to remove the brain. The isolated whole brains were placed in an ice-cold modified aCSF solution containing (in $\mathrm{mM}$ ) 175 sucrose, $20 \mathrm{NaCl}, 3.5 \mathrm{KCl}, 1.25 \mathrm{NaH}_{2} \mathrm{PO}_{4}, 26 \mathrm{NaHCO}_{3}$, $1.3 \mathrm{MgCl}_{2}$, and $11 \mathrm{D}$-(+)-glucose. Solutions were then gassed with $95 \% \mathrm{O}_{2} / 5 \% \mathrm{CO}_{2}$. Coronal slices $(300 \mu \mathrm{m})$ including the LA were cut using a vibroslicer (NVSL, World Precision Instruments) incubated in normal aCSF containing (in $\mathrm{mM}$ ) $120 \mathrm{NaCl}, 3.5 \mathrm{KCl}, 1.25 \mathrm{NaH}_{2} \mathrm{PO}_{4}, 26 \mathrm{NaHCO}_{3}, 1.3 \mathrm{MgCl}_{2}$, $2 \mathrm{CaCl}_{2}$, and $11 \mathrm{D}-(+)$-glucose, and continuously bubbled at room temperature with $95 \% \mathrm{O}_{2} / 5 \% \mathrm{CO}_{2}$. Just before transferring a slice to the recording chamber, the cortex overlying the LA was cut away with a scalpel so that cortical epileptic burst discharges would not invade the LA.

\section{Afferent Stimulation and Recording Conditions}

The cortical and thalamic afferents were stimulated at a frequency of $0.067 \mathrm{~Hz}$ with a concentric bipolar electrode (CBAEC75, FHC Inc., Bowdoin, ME). For cortical afferent stimulation, a stimulating electrode was placed on the external capsule fibers located approximately $50 \mu \mathrm{m}$ above the dorsal tip of the LA. Thalamic afferents were stimulated using a bipolar electrode that was placed on the midpoint of the trunk between the internal capsule and the medial boundary of the LA. All recordings were performed in cells located beneath the midpoint of the trunk, spanning the LA horizontally. To record EPSCs in principal neurons of the LA, we included picrotoxin $(100 \mu \mathrm{M})$ in the recording solution to isolate excitatory synaptic transmission and to block feedforward GABAergic inputs to principal neurons in the LA. To record miniature inhibitory postsynaptic currents

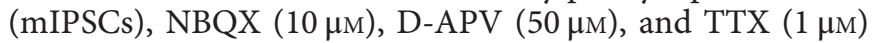
were included in the recording solution. The principal cells were identified on the basis of the pyramidal shape of their somata and the size or the decay time of their spontaneous EPSCs.

\section{Whole-Cell Patch-Clamp Recordings}

Whole-cell recordings were made using an Axopatch $200 \mathrm{~A}$ (MDS Analytical Technologies, Sunnyvale, CA). Recordings were obtained using pipettes with resistances of $3.5 \sim 4.5 \mathrm{M} \Omega$ and filled with the following solution (in $\mathrm{mM}$ ): 100 Cs-gluconate or $\mathrm{CsCl}$ (for mIPSC recording), 0.6 EGTA, 10 HEPES, $5 \mathrm{NaCl}, 20$ TEA, 4 Mg-ATP, $0.3 \mathrm{Na}$-GTP, and 3 QX314, with the $\mathrm{pH}$ adjusted to 7.2 with $\mathrm{CsOH}$ and the osmolarity adjusted to approximately $297 \mathrm{mmol} / \mathrm{kg}$ with sucrose. Recordings were made under IR-DICenhanced visual guidance from neurons that were three to four cell layers below the surface of $300-\mu \mathrm{m}$-thick slices at
$32.0 \pm 1.0^{\circ} \mathrm{C}$. Neurons were voltage-clamped at $-70 \mathrm{mV}$, and solutions were delivered to slices via superfusion driven by a peristaltic pump at a flow rate of $1.3 \mathrm{ml} / \mathrm{min}$. Series resistance was monitored throughout the experiments, and if it changed by $>20 \%$, the data were discarded. Whole-cell currents were filtered at $1 \mathrm{kHz}$, digitized at up to $20 \mathrm{kHz}$, and stored on a microcomputer (Clampex 8 software, Molecular Devices). All recordings were completed within $5 \mathrm{~h}$ after slice preparation. One or two neurons were recorded per animal (a neuron per slice). The measurements of the input-output curves and paired-pulse ratios (PPR) were started $10 \mathrm{~min}$ after whole-cell configuration. Input-output curves were constructed by varying stimulus intensity from 0 to $40 \mu \mathrm{A}$ with a $5 \mu \mathrm{A}$ step size, and the output level of each stimulus was determined by an average of five consecutive responses. The mIPSCs were analyzed using MiniAnalysis software (Synaptosoft, Decatur, GA) with the criteria of a $<4 \mathrm{~ms}$ rise time and $<10 \mathrm{~ms}$ decay time. The detection threshold was set at three times the root mean square (RMS) noise, and there was no significant difference in RMS noise between the experimental groups (vehicle-infused group, $2.71 \pm 0.14 \mathrm{pA}$, $n=8$; LY341495-treated group, $2.60 \pm 0.12 \mathrm{pA}, n=8$; unpaired $t$-test, $P=0.5770$ ). For each cell, a sequential stretch of 300 mIPSCs was used to analyze the averaged amplitude and frequency. In the ppLFS protocol, stimulation for $5 \mathrm{~min}$ at $1 \mathrm{~Hz}$ was performed using a paired pulse $(50 \mathrm{~ms}$ interpulse interval) while the neuron was clamped at $-50 \mathrm{mV}$, as described previously (Hong et al, 2009). EPSC amplitudes were normalized to an average of baseline responses for the first $10 \mathrm{~min}$ and were expressed as percentage of the average baseline responses.

\section{Statistical Analyses}

Between-group data comparisons were conducted using either a two-sided unpaired $t$-test or one-way ANOVA with a subsequent Newman-Keuls post hoc comparison. Two-way ANOVA was used to analyze the effect of groups on trials during extinction training. $P<0.05$ was considered indicative of statistical significance. All the values are expressed as the means \pm SEM.

\section{RESULTS}

\section{Activation of mGluR2/3 in the LA is Required for Fear Extinction}

mGluR1/5 and mGluR7 have been shown to be crucial for fear extinction, but the involvement of mGluR2/3 in fear extinction has not been examined. To determine whether the activity of mGluR2/3 in the LA is required for fear extinction, we used the microinfusion of LY341495, a highly specific mGluR2/3 antagonist, directly into the LA (Walker et al, 2002; Chi et al, 2006; Sakagami et al, 2008).

Rats that were bilaterally implanted with cannulas into the LA underwent fear conditioning. Fear conditioning consisted of three tone-shock parings. Forty-eight hours after conditioning, either LY341495 or vehicle was administered into the LA, and fear extinction was conducted $15 \mathrm{~min}$ after the infusion. Extinction consisted of 20 CS presentations without foot shock, and extinction retention was tested the next day (Figure 1a). To avoid possible bias, freezing responses to the 

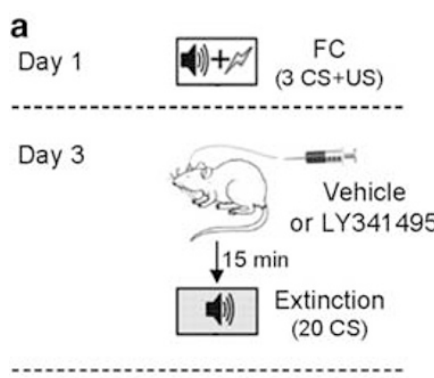

Day 4

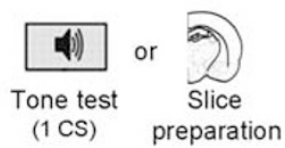

b
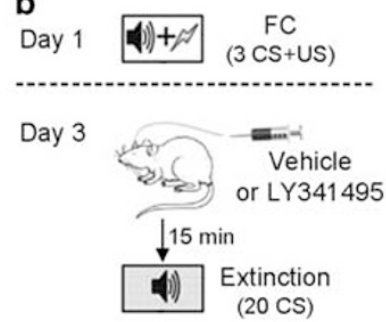

Day 4

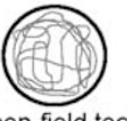

c

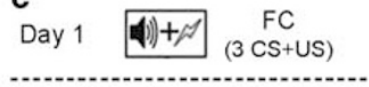

Day 3

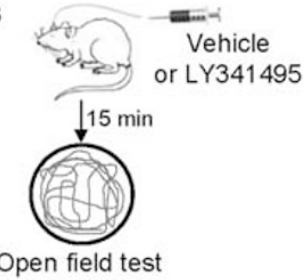

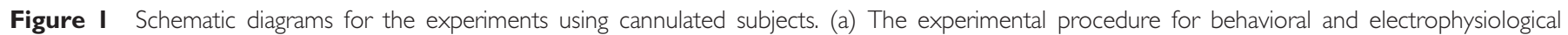
experiments in Figures 2, 4 and 6. (b and c) The behavioral procedure for the open-field test in Figure 3a-c and Figure 3d-f, respectively.

CS were quantified by a trained observer in a blind manner. Rats that were infused with LY341495 displayed robust freezing in the first CS block of extinction, similar to vehicle-infused controls (vehicle, 66.56 $\pm 3.83 \%, n=9$; LY341495, $71.85 \pm 5.27 \%, n=10$; unpaired $t$-test, $t=0.7957$, $P=0.4372$; Figures $2 \mathrm{a}$ and $\mathrm{b}$ ). CS-induced freezing responses of the two groups progressively decreased to a similar extent during extinction training. A two-way ANOVA revealed a significant main effect of trial $\left(\mathrm{F}_{(9,153)}=21.9, P<0.0001\right)$ and insignificant group $\times$ trial interaction $\left(\mathrm{F}_{(9,153)}=0.7465\right.$, $P=0.6658)$. However, when extinction retention was tested $24 \mathrm{~h}$ after extinction training, the LY341495-infused group showed higher freezing levels relative to vehicle-infused controls (vehicle, $33.92 \pm 8.73 \%, n=9$; LY341495, 60.87 \pm $7.77 \%, n=10$; unpaired $t$-test, $t=2.315, P=0.0334$; Figure $2 \mathrm{a}$ and $b)$, suggesting that extinction retention requires mGluR2/3 activity in the LA. We then tested the possibility that the blockade of mGluR2/3 simply altered conditioned fear responses regardless of extinction training. To test this, separate groups of rats were utilized as context controls that underwent fear conditioning and were exposed just to the extinction context for the same period as the extinction groups but without extinction training. The context exposure was conducted $48 \mathrm{~h}$ after conditioning, and LY341495 was microinjected into the LA $15 \mathrm{~min}$ before the context exposure. A retention test was performed $24 \mathrm{~h}$ after the context exposure. LY341495- or vehicle-infused context controls showed similar freezing levels in the retention test (vehicle, $73.68 \pm 9.29 \%, \quad n=7 ; \quad$ LY341495, 83.38 $2.32 \%, \quad n=6$; unpaired $t$-test, $t=0.9396, P=0.3676$; Figure $2 \mathrm{a}$ and $\mathrm{b}$ ). This indicates that the LY341495 effect requires extinction training.

We then tested state-dependent effects of LY341495 on blockade of extinction retention; that is, when LY341495 is injected only before extinction training, original fear memory may relapse upon retention test in the absence of LY341495 injection because the animal may recognize the retention test in the absence of LY341495 as a different 'state' (as in context renewal) (Bouton et al, 1990). To test this, LY341495 or vehicle was infused into the LA 15 min before extinction training and retention test (Figure $2 \mathrm{c}$ and $\mathrm{d}$ ). The LY341495-infused group showed higher freezing levels upon retention test relative to vehicle-infused controls (vehicle,
$29.22 \pm 7.00 \%, n=6$; LY341495, $53.16 \pm 7.55 \%, n=6$; unpaired $t$-test, $t=2.324, P=0.0425$; Figure $2 \mathrm{c}$ and $\mathrm{d}$ ). Thus, these findings do not support state-dependent effects of LY341495 and further suggest that the LY341495 effects are exerted during extinction training.

We then tested whether the LY341495 effect was limited to the LA. For this, we microinfused LY341495 into the CeA adjacent to the LA. LY341495 was microinfused into the CeA $15 \mathrm{~min}$ before extinction training, and extinction retention was tested $24 \mathrm{~h}$ after extinction training. LY341495 microinfusion had no significant effects on either extinction training (Two-way ANOVA, group $\times$ interaction, $\mathrm{F}_{(9,99)}=0.9519, P=0.4844$, main effect of trial, $\mathrm{F}_{(9,99)}=28.18$, $P<0.0001$ ) or retention (vehicle, $24.55 \pm 7.47 \%, n=8$; LY341495, 27.76 $\pm 8.36 \%, n=5$; unpaired $t$-test, $t=0.2776$, $P=0.7865$; Figure $2 \mathrm{e}$ and $\mathrm{f})$. Together, these results suggest that activation of $\mathrm{mGluR} 2 / 3$ in the LA during extinction training is required for extinction retention.

Previous studies have shown that mGluR2/3 is involved in anxiety (Linden et al, 2005; Swanson et al, 2005). Thus, it is possible that LY341495 produces some complications in assessing conditioned fear responses during extinction training or the retention test because conditioned fear responses (ie, freezing) are easily altered by locomotive changes due to anxiety.

To test whether microinfusion of LY341495 into the LA alters locomotive activity during extinction training or at the retention test, we used the open-field test (see Figure 1b and c). We first assessed effects of LY341495 on locomotive activity during a period when extinction training had been performed. LY341495 (or vehicle) was infused into the LA $48 \mathrm{~h}$ after conditioning, and rats were placed in the open field $15 \mathrm{~min}$ after the infusion (Figure $3 \mathrm{a}-\mathrm{c}$ ). The total distance travelled and average velocity appeared similar in the two groups (vehicle, $n=7$, LY341495, $n=6$; total distance, vehicle, $4903 \pm 362.3 \mathrm{~cm}$, LY341495, $4885 \pm 460.3 \mathrm{~cm}$, unpaired $t$-test, $t=0.0321, P=0.975$; velocity, vehicle, $8.17 \pm$ $0.60 \mathrm{~cm} / \mathrm{s}, \quad \mathrm{LY} 341495, \quad 8.14 \pm 0.77 \mathrm{~cm} / \mathrm{s}$, unpaired $t$-test, $t=0.0324, P=0.9747$; Figure $3 \mathrm{c}$ ). This indicates that microinfusion of LY341495 into the LA does not alter locomotor activity during a period when extinction training had been performed. Moreover, the two groups visited the center zone similarly (time in center, vehicle, $19.33 \pm 5.28$ s, LY341495, 
a

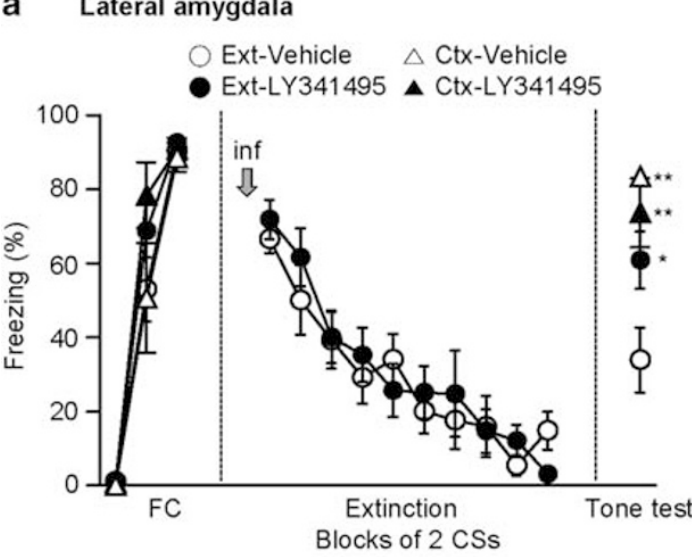

C Lateral amygdala - Double infusion

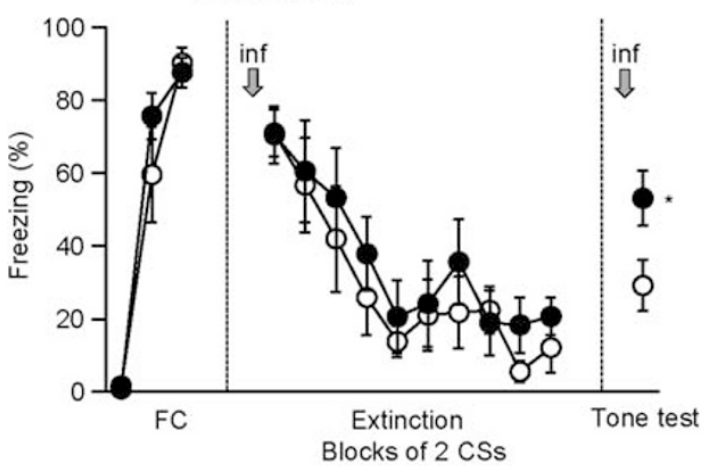

e Central amygdala

CeA-Vehicle

- CeA-LY341495

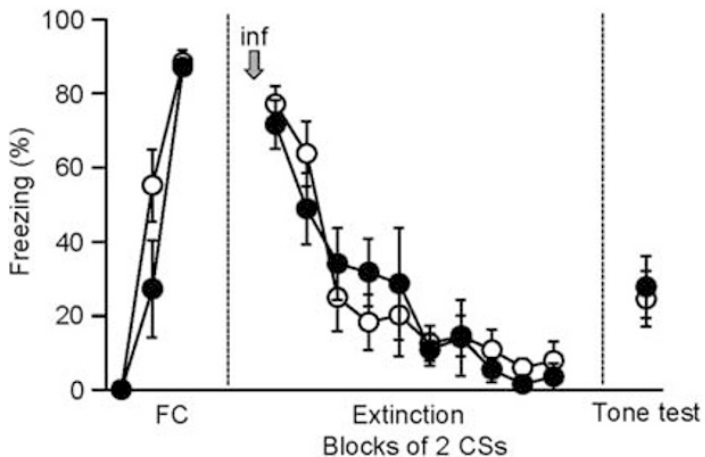

b

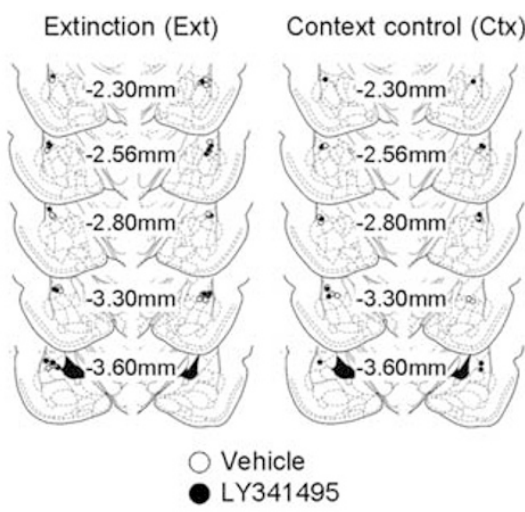

d

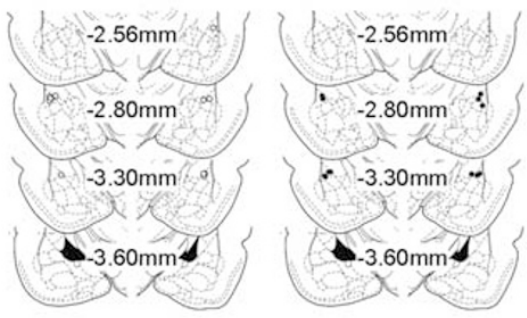

Vehicle

LY341495

f

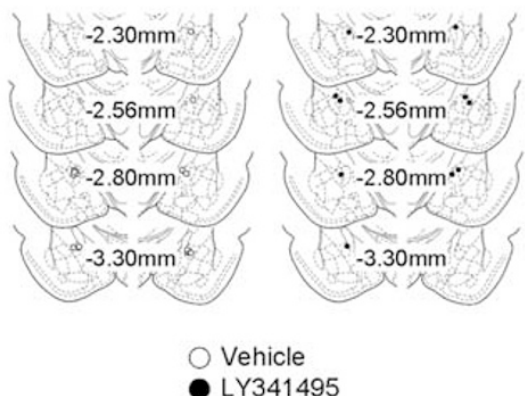

- LY341495

Figure $2 \mathrm{mGluR2/3}$ in the LA, but not in the CeA, is required for fear extinction. (a) Freezing responses of the groups in which LY34I 495 (or vehicle) was infused into the LA (open circle, vehicle-infused extinction group, $n=9$; filled circle, LY34I 495-infused extinction group, $n=10$; open triangle, vehicle-infused context controls, $n=6$; filled triangle, LY34I495-infused context controls, $n=7$ ). The data for extinction training were analyzed in blocks of two trials. (b) Schematic illustration showing cannula tip placements. Left, cannula tip placements for the experiments shown in a. Right, cannula tip placements for context control groups (open circle, vehicle-infused group; filled circle, LY34I495-infused group). The illustration was adopted from the atlas of Paxinos and Watson (1998). (c) Freezing responses of the groups in which LY34I 495 (or vehicle) was infused into LA before extinction training and retention (open circle, vehicle-infused group, $n=6$; filled circle, LY34I495-infused group, $n=6$ ). (d) Schematic illustration showing cannula tip placements for the experiments shown in c. (e) Freezing responses in the groups in which LY34I495 (or vehicle) was infused into the CeA (open circle, vehicle-infused extinction group, $n=8$; filled circle, LY34|495-infused extinction group, $n=5$ ). (f) Schematic illustration showing cannula tip placements for the experiments shown in e. Error bars indicate SEM.

$26.03 \pm 7.44 \mathrm{~s}$, unpaired $t$-test, $t=0.7502, P=0.4689$; number of center entries, vehicle, $13.14 \pm 4.43$, LY341495, $12.00 \pm$ 2.39, unpaired $t$-test, $t=0.2151, P=0.8336$; Figure $3 \mathrm{c}$ ), suggesting similar anxiety levels between the two groups.
We then assessed the long-term effect of LY341495 on locomotive activity during a period when extinction retention had been tested. LY341495 (or vehicle) was infused into the LA $48 \mathrm{~h}$ after conditioning, extinction training was 
a
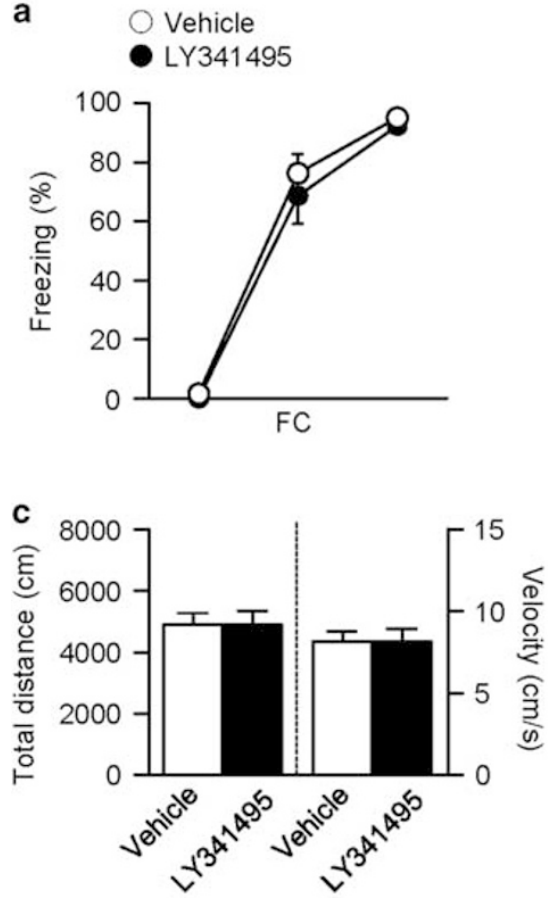

d
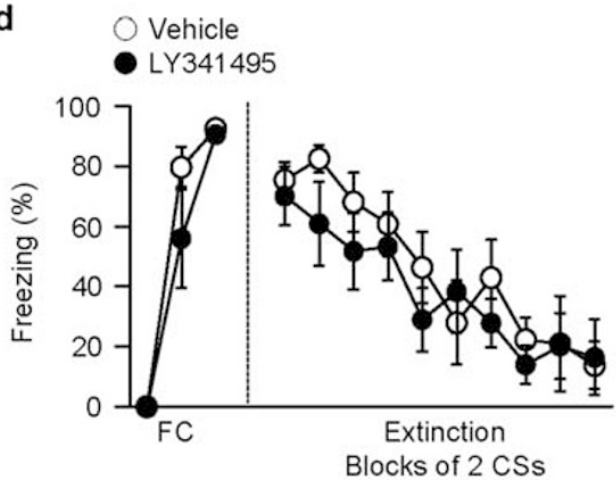

b
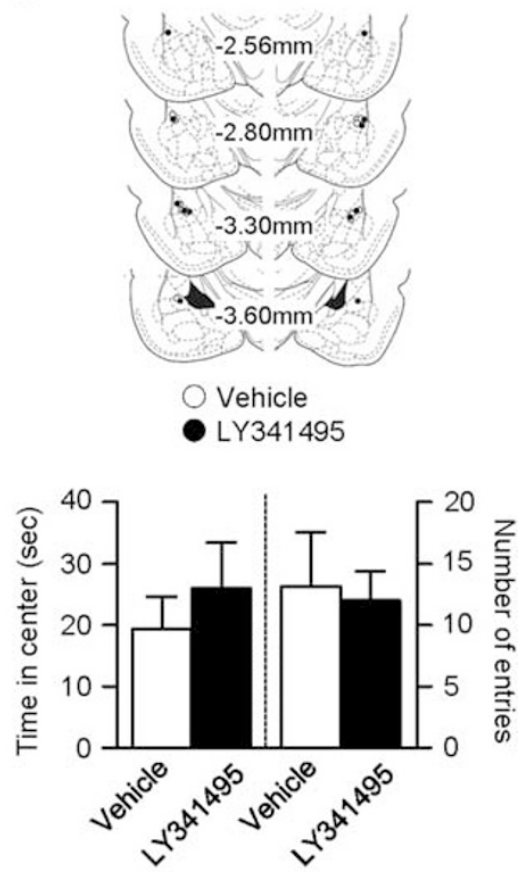

e
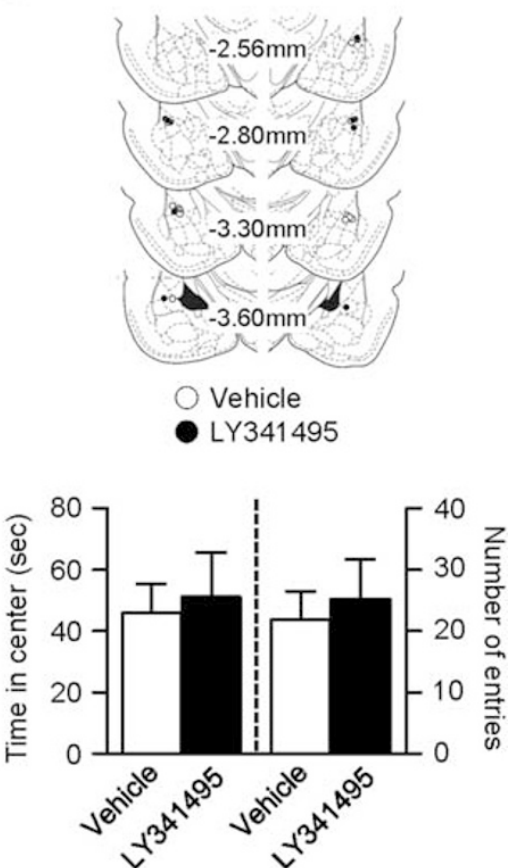

Figure 3 Blockade of mGluR2/3 does not alter locomotive activity or anxiety. (a) Freezing responses to fear conditioning for the groups in which LY34I 495 (or vehicle) was microinfused into the LA (open circle, vehicle-infused controls, $n=7$; filled circle, LY34I 495-infused group, $n=6$ ). (b) Schematic illustration of cannula tip placements for the experiments shown in a and c. (c) No significant changes in locomotive activity by microinfusion of LY34I495 $24 \mathrm{~h}$ after conditioning (vehicle-infused controls, $n=7$; LY34|495-infused group, $n=6$ ). Locomotive activity was assessed I 5 min after the infusion. Left, total distance travelled and velocity in the two groups. Right, the time in the center of open field and the number of center entries in the two groups. (d) Freezing responses to fear conditioning and subsequent extinction for the groups in which LY34I495 (or vehicle) was microinfused into the LA (open circle, vehicle-infused controls, $n=6$; filled circle, LY34I495-infused group, $n=6$ ). (e) Schematic illustration of cannula tip placements for the experiments shown in $d$ and $f$. ( $f$ ) No significant changes in locomotive activity by microinfusion of LY34I $49524 \mathrm{~h}$ after conditioning (vehicle-infused group, $n=6$; LY34I 495-infused group, $n=6$ ). Locomotive activity was assessed $24 \mathrm{~h}$ after extinction training. Left, total distance and velocity measured for locomotion assessment. Left, total distance travelled and velocity in the two groups. Right, the time in the center of the open field and the number of center entries in the two groups. Error bars indicate SEM. 
performed 15 min after the infusion, and the rats were placed in the open field $24 \mathrm{~h}$ after extinction training (Figure $3 \mathrm{~d}-\mathrm{f}$ ). Anxiety and mobility were not significantly different between the two groups (vehicle, $n=6$, LY341495, $n=6$; total distance, vehicle, $5706 \pm 320.9 \mathrm{~cm}$, LY341495, $6290 \pm$ $612.5 \mathrm{~cm}$, unpaired $t$-test, $t=0.8453, P=0.4177$; velocity, vehicle, $\quad 9.51 \pm 0.53 \mathrm{~cm} / \mathrm{s}, \quad L Y 341495, \quad 10.48 \pm 1.02 \mathrm{~cm} / \mathrm{s}$, unpaired $t$-test, $t=0.8459, P=0.4174$; time in center, vehicle, $45.94 \pm 9.42 \mathrm{~s}$, LY341495, $51.02 \pm 14.66 \mathrm{~s}$, unpaired $t$-test, $t=0.2913, P=0.7768$; number of center entries, vehicle, $21.83 \pm 4.65$, LY341495, $25.17 \pm 6.47$, unpaired $t$-test, $t=0.4185, \quad P=0.6845$; Figure $3 \mathrm{f}$ ). This indicates that LY341495 microinfusion with extinction training does not alter locomotor activity during a period when extinction retention had been tested. Together, these results suggest that the effects of LY341495 on extinction training and retention are not due to altered mobility.

\section{Activation of mGluR2/3 is Required for a Presynaptic Long-Term Weakening of C-LA Synaptic Efficacy After Extinction Training}

We have so far demonstrated that activation of mGluR2/3 during extinction training is required for extinction retention. We next determined how mGluR $2 / 3$ contributes to fear extinction. It has been reported that $\mathrm{mGluR} 2 / 3$ is mainly expressed presynaptically and that it preferentially modulates presynaptic function (Swanson et al, 2005). Furthermore, C-LA synapses, one of the major input synapses onto the LA, are known to display presynaptic enhancements following fear conditioning (Tsvetkov et al, 2002; Schroeder and Shinnick-Gallagher, 2005). On the basis of these previous findings, we hypothesized that activation of mGluR2/3 leads to a presynaptic long-term weakening of C-LA synapses after extinction training, resulting in lessened fear responses during extinction retention. In our previous study, we reported that C-LA synaptic efficacy increases after fear conditioning and decreases after extinction training (Hong et al, 2009). The activation of $\mathrm{mGluR} 2 / 3$ has been shown to induce synaptic weakening at CNS synapses, including amygdala synapses (Lin et al, 2005; Hong et al, 2009; Lodge et al, 2013; Lucas et al, 2013). We therefore examined whether the blockade of mGluR2/3 disrupts the C-LA synaptic weakening that results from extinction training.

Rats were bilaterally implanted with cannulas into the LA and underwent fear conditioning and extinction (see Figure 1a). LY341495 (or vehicle) was infused into the LA 15 min before extinction training. Amygdala slices were prepared to measure the synaptic efficacy at C-LA synapses using whole-cell recordings $24 \mathrm{~h}$ after extinction training. Cannulas were carefully removed after decapitation and brain slices were prepared. We only used animals in which the tip of the injector cannula was placed correctly within the LA of both hemispheres, and we made whole-cell recordings from the two coronal slices just anterior and posterior to the slice containing the tip.

The input-output relationships for the EPSC amplitude as a function of afferent fiber stimulus intensity were compared between groups. The slope of the linear fit to the inputoutput relationship obtained in each neuron was averaged within each group. The synaptic efficacy was significantly greater in the LY341495-infused group relative to vehicle- infused controls (vehicle, $4.22 \pm 0.53 \mathrm{pA} / \mu \mathrm{A}, n=9$ from eight rats; LY341495, $7.71 \pm 1.16 \mathrm{pA} / \mu \mathrm{A}, n=10$ from eight rats; unpaired $t$-test, $t=2.625, P=0.0177$; Figure $4 \mathrm{a}$ and $\mathrm{b}$ ). This result suggests that the blockade of mGluR2/3 during extinction training impairs the extinction-induced weakening of C-LA synaptic efficacy.

To determine whether the LY341495 effect is specific to C-LA synapses, we examined the excitatory synaptic efficacy at thalamic input synapses onto the LA (T-LA synapses), another major input synapse onto the LA. In contrast to the results from the C-LA synapse, LY341495 microinfusion into the LA had no significant effects on excitatory synaptic efficacy at T-LA synapses (vehicle, $9.04 \pm 1.25 \mathrm{pA} / \mu \mathrm{A}, n=9$ from eight rats; LY341495, $9.34 \pm 1.58 \mathrm{pA} / \mu \mathrm{A}, n=9$ from seven rats; unpaired $t$-test, $t=0.1497, P=0.8829$; Figure $4 \mathrm{~d}$ and $\mathrm{e}$ ). In addition, we examined inhibitory synaptic transmission in principal neurons of the LA by measuring the frequency and amplitude of mIPSCs. The frequency or amplitude of mIPSCs was not significantly different between the LY341495-infused group and vehicle-infused controls (vehicle, $n=8$ from five rats, LY341495, $n=8$ from five rats; frequency, vehicle, $5.66 \pm$ $0.24 \mathrm{~Hz}, \mathrm{LY} 341495,5.32 \pm 0.29 \mathrm{~Hz}$, unpaired $t$-test, $t=0.8973$, $P=0.3847$; amplitude, vehicle, $34.07 \pm 2.07 \mathrm{pA}$, LY341495, $30.50 \pm 1.99 \mathrm{pA}$, unpaired $t$-test, $t=1.244, \quad P=0.2341$; Figure 4f). Therefore, LY341495 microinfusion into the LA appears to specifically affect C-LA synapses without altering other excitatory or inhibitory synapses in the LA.

Fear conditioning has been shown to produce an increase in presynaptic release probability at C-LA synapses (Tsvetkov et al, 2002). However, it has not been determined whether extinction involves a decrease in release probability at C-LA synapses, though extinction results in a decrease in C-LA synaptic efficacy (Hong et al, 2009). In addition, mGluR2/3 is thought to primarily modulate presynaptic release probability (Swanson et al, 2005), and hence, it is possible that activation of $\mathrm{mGluR} 2 / 3$ during extinction training leads to a weakening of C-LA synaptic efficacy.

Therefore, we determined whether the conditioninginduced increase in presynaptic release probability at C-LA synapses decreases after extinction training. To test this, we used the paired-pulse ratio (PPR) of EPSCs, which is known to inversely correlate with presynaptic release probability (Zucker, 1989). To avoid possible changes in synaptic properties caused by the retention test, one set of rats was killed to prepare brain slices and another set was used to monitor conditioned freezing (Figure 5a). Extinction training produced a decrease in freezing (which was assessed $24 \mathrm{~h}$ after the extinction training) relative to the conditioned group (conditioned, $81.61 \pm 1.91 \%, n=8$; extinction, $46.25 \pm 8.21 \%, n=7$; unpaired $t$-test, $t=4.472, P=0.0006$, Figure 5b). As in a previous study (Tsvetkov et al, 2002), PPR was reduced significantly in the conditioned group. Consistent with our prediction, PPR in the extinction group was enhanced relative to the conditioned group and was not significantly different from PPR in naïve controls $(50 \mathrm{~ms}$ inter-pulse interval; naive, $1.28 \pm 0.04, n=6$ from four rats; conditioned, $1.11 \pm 0.03, n=13$ from eight rats; extinction, $1.31 \pm 0.07, n=8$ from four rats; One-way ANOVA, $\mathrm{F}_{(2,26)}=5.522, P=0.0106$; conditioned $v s$ naive or extinction, $P<0.05$, Newman-Keuls post hoc test; Figure 5c). This suggests that extinction training reduces release probability at C-LA synapses in extinction retention. 
a

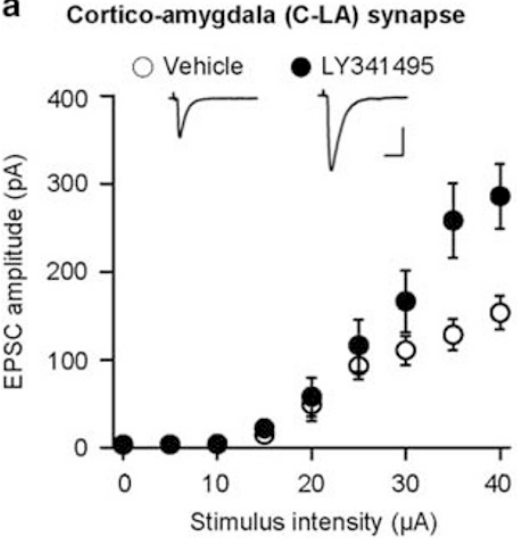

d

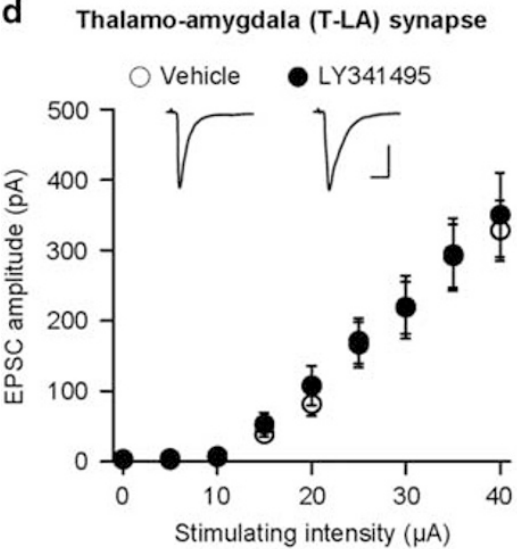

b

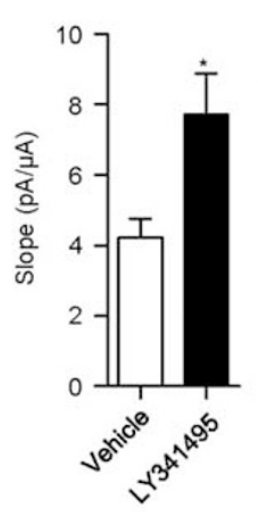

e

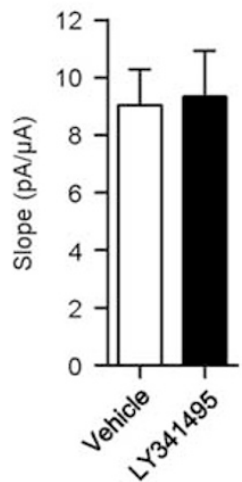

C

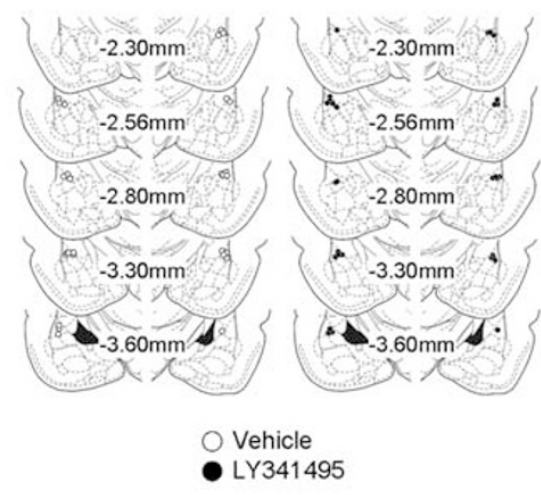

f

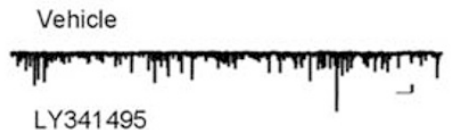

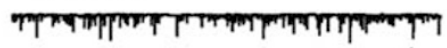
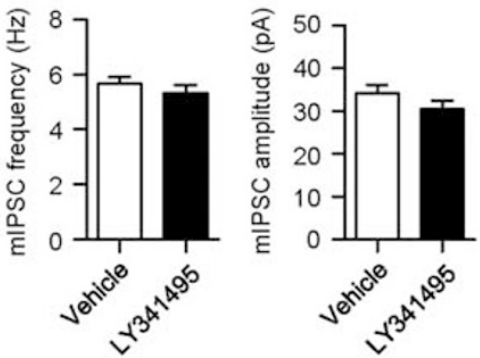

Figure 4 Microinfusion of LY34I495 into the LA attenuates the extinction-induced weakening of C-LA synaptic efficacy, but has no significant effect at T-LA synapses or inhibitory synapses in principal neurons of the LA. (a) Input-output curves for EPSCs at C-LA synapses in vehicle- and LY34I495-infused groups (vehicle-infused group, $n=9$ from eight rats; LY34 I 495-infused group, $n=10$ from eight rats). Representative traces are an average of five consecutive responses with input stimulations of $35 \mu \mathrm{A}$ (scale bars, $10 \mathrm{~ms}$ and I00 pA). (b) The slope of the input-output curve in the LY34I495 group was significantly larger than that in vehicle-infused controls. $* P<0.05$. (c) Schematic illustration showing cannula tip placement for the electrophysiological experiments shown in this figure and Figure 5. Left, cannula tip placements for vehicle-infused group (open circle). Right, cannula tip placements for the LY34 I495-infused group (filled circle). (d) Input-output curves for EPSCs at T-LA synapses in vehicle- and LY34I 495-infused groups (vehicle-infused group, $n=9$ from eight rats; LY34|495-infused group, $n=9$ from seven rats). Representative traces are an average of five consecutive responses with input stimulations of $35 \mu \mathrm{A}$ (scale bars, $10 \mathrm{~ms}$ and $200 \mathrm{pA}$ ). (e) The slope of the input-output curve at T-LA synapses in the LY34I495 did not differ significantly from that of vehicle-infused controls. (f) The frequency and amplitude of mIPSC in LA principal neurons from vehicle- and LY34I 495 -infused groups (vehicle-infused group, $n=8$ from five rats; LY34 | 495-infused group, $n=8$ from five rats; scale bars, I $s$ and $50 \mathrm{pA}$ ).

We next determined whether mGluR $2 / 3$ is required for the extinction-induced decrease in release probability. To test this, we microinfused LY341495 (or vehicle) into the LA 15 min before extinction training, and we prepared brain slices $24 \mathrm{~h}$ after the training. PPR at C-LA synapses was enhanced in the LY341495-infused group relative to vehicleinfused controls (vehicle, $1.29 \pm 0.07, n=8$ from seven rats; LY341495, $1.02 \pm 0.05, n=9$ from six rats; unpaired $t$-test, $t=3.029, P=0.0085$; Figure $5 \mathrm{~d}$ ). In contrast, PPR at T-LA synapses was not significantly different between the two groups (vehicle, $1.17 \pm 0.06, n=6$ from four rats; LY341495, $1.11 \pm 0.06, n=10$ from eight rats; unpaired $t$-test, $t=0.5567$, $P=0.5865$; Figure 5e). Taken together, our data suggest that activation of mGluR2/3 is required for the extinctioninduced decrease in release probability at C-LA synapses.

We have previously proposed that a form of synaptic depression at C-LA synapses (which is induced by paired pulse low-frequency stimulation (ppLFS)) underlies fear extinction, as supported by the occlusion of this synaptic depression after extinction training, and that induction of ppLFS-induced synaptic depression depends upon mGluR2/3 activity (Hong et al, 2009). We therefore tested whether the blockade of mGluR2/3 during extinction training relieves the occlusion of ppLFS-induced synaptic depression at C-LA synapses. We microinfused LY341495 (or vehicle) into the LA 15 min before extinction training and prepared brain slices $24 \mathrm{~h}$ after the training. The ppLFS-induced synaptic depression was occluded in extinguished vehicle controls as shown previously (Hong et al, 2009), whereas preinjection of LY341495 with extinction training blocked this occlusion and resulted in robust ppLFS-induced depression (vehicle, $93.09 \pm 1.79 \%, n=6$ from four rats; LY341495, $83.30 \pm 3.24 \%, n=6$ from six rats; unpaired $t$-test, $t=3.677, P=0.0244$; Figure $6 \mathrm{a}$ and $\mathrm{b}$ ). This suggests that the blockade of mGluR2/3 during extinction training prevents the recruitment of ppLFS-induced depression-like plasticity 


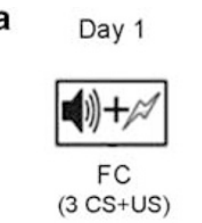

b

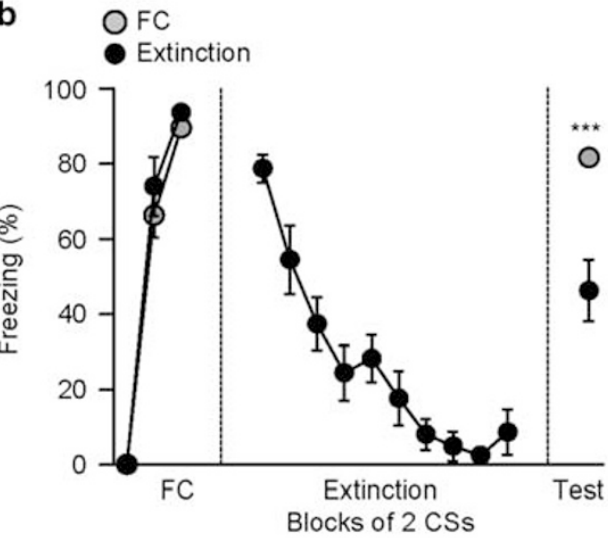

d

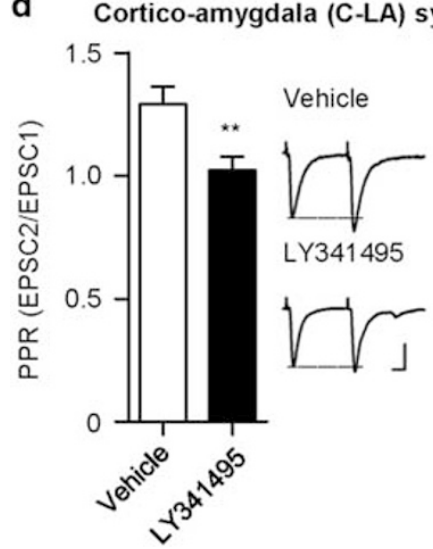

Day 4

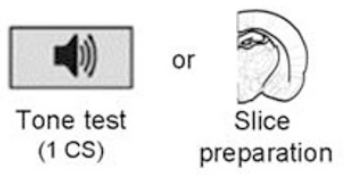

C

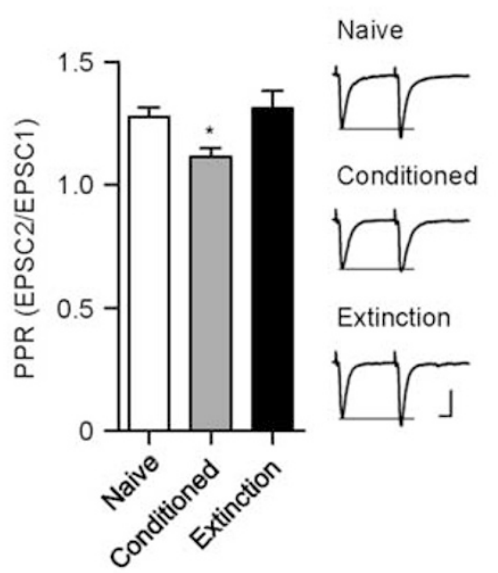

e Thalamo-amygdala (T-LA) synapse

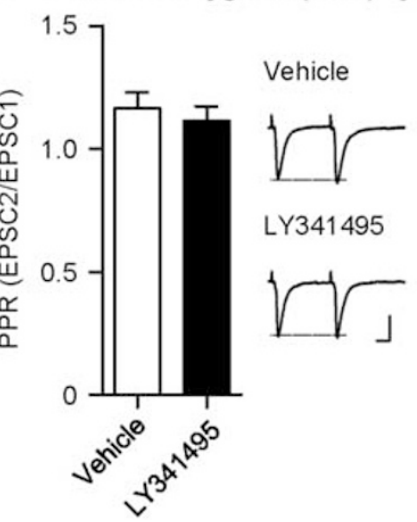

Figure 5 Fear conditioning reduces and extinction training enhances PPR. Microinfusion of LY34I495 into the LA blocks the extinction-induced enhancement in PPR at C-LA synapses but not T-LA synapses. (a) The behavioral procedure for the experiments shown in b-c. (b) Freezing responses in the conditioned and extinction groups. A day after extinction training, one set of rats was killed to prepare brain slices, and another set was used to monitor conditioned freezing for the retention test (conditioned group, $n=8$; extinction group, $n=7$ ). (c) PPR of AMPA EPSCs at C-LA synapses in naive controls, conditioned, and extinction groups (naive controls, $n=6$ from four rats; conditioned group, $n=13$ from eight rats; extinction group, $n=8$ from four rats). Representative traces show an average of ten consecutive responses (scale bars, 10 ms and 50 pA). *P $<0.05$. (d) PPR of AMPA EPSCs at C-LA synapses in vehicle- and LY34|495-infused groups (vehicle-infused group, $n=8$ from seven rats; LY34I495-infused group, $n=9$ from six rats). *** $<0.01$. (e) PPR of AMPA EPSCs at T-LA synapses in vehicle- and LY34 I495-infused groups (vehicle-infused group, $n=6$ from four rats; LY34 I 495-infused group, $n=10$ from eight rats). Representative traces in $\mathrm{d}$ and e are an average of $8-10$ consecutive responses (scale bars, $10 \mathrm{~ms}$ and 20 pA).

in vivo, which allows for successful induction of ppLFSinduced depression in brain slices prepared after the training. As a control experiment, we next determined whether the blockade of mGluR2/3 alters another form of ppLFS-induced synaptic depression at T-LA synapses, which depends on group I metabotropic receptors (Kim et al, 2007b). ppLFS-induced synaptic depression was occluded in extinguished vehicle controls as shown previously (Kim et al, 2007b), but pre-injection of LY341495 with extinction training failed to block this occlusion (vehicle, $94.64 \pm 2.18 \%, n=9$ from six rats; LY341495, $93.92 \pm 6.04 \%$, $n=9$ from seven rats; unpaired $t$-test, $t=0.1120, P=0.9122$; Figure $6 \mathrm{c}$ and d). This indicates that the extinction training with pre-injection of LY341495 does not change ppLFSinduced depression at T-LA which is group I mGluRdependent (Kim et al, 2007b). Together, these findings suggest that activation of mGluR2/3 during extinction training recruits a long-term weakening of C-LA synaptic efficacy that shares some mechanisms with ppLFS-induced depression.

\section{DISCUSSION}

In this study, we have shown that the activation of mGluR2/3 in the LA is required for fear extinction and that fear extinction recruits mGluR2/3-dependent presynaptic 


\section{a}

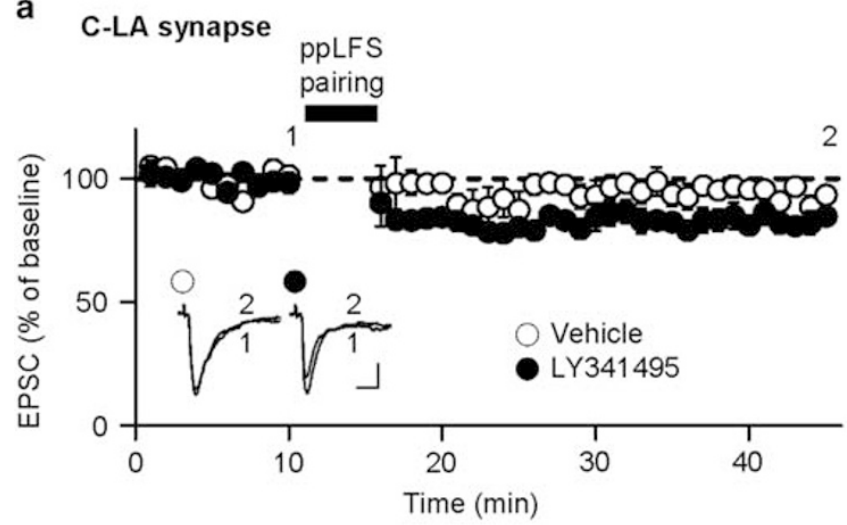

b

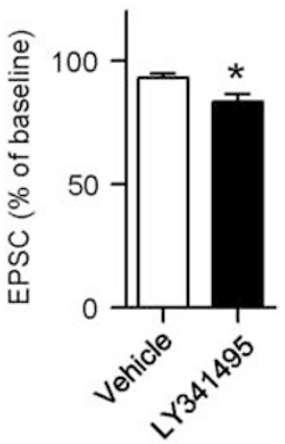

d

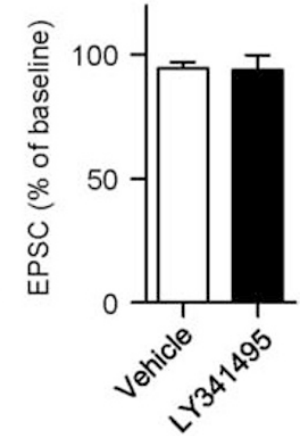

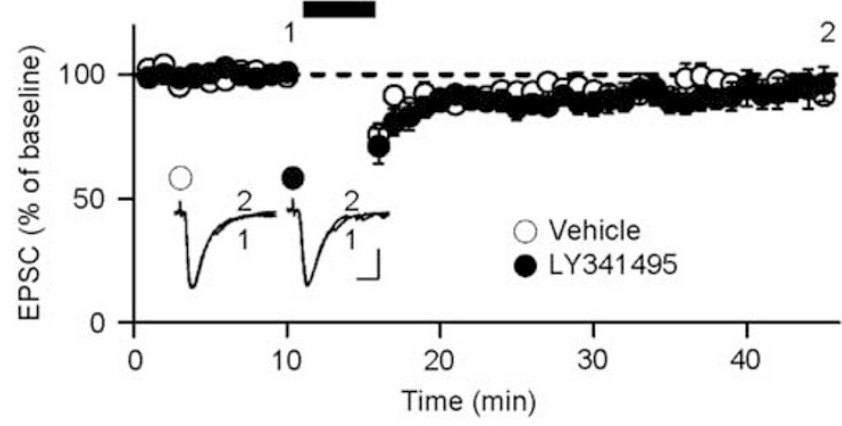

e

\section{T-LA synapse}

ppLFS

\section{pairing}

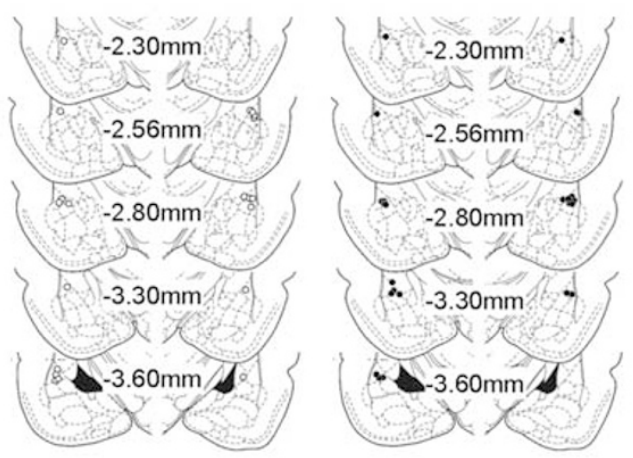

Vehicle

LY341495

Figure 6 Microinfusion of LY34I495 into the LA relieves the extinction-induced occlusion of ppLFS-induced synaptic depression at C-LA synapses, but not at T-LA synapses which is group I mGluRs-dependent. (a) EPSC amplitudes of C-LA synapses were plotted as a function of the recording time in vehicle- and LY34I 495-infused groups (vehicle-infused group, $n=6$ from four rats; LY34I 495-infused group, $n=6$ from six rats). The inset shows representative traces in each group (an average of four consecutive responses; scale bars, $10 \mathrm{~ms}$ and $50 \mathrm{pA}$ ). (b) Summary data for the experiments shown in a. A temporal average of the data points during the period of interest (the last $5 \mathrm{~min}$ ) was used for the results and statistical comparison. (c) EPSC amplitudes of T-LA synapses were plotted as a function of the recording time in vehicle- and LY34| 495-infused groups (vehicle-infused group, $n=9$ from six rats; LY34| 495-infused group, $n=9$ from seven rats). The inset shows representative traces in each group (an average of four consecutive responses; scale bars, 10 ms and 50 pA). (d) Summary data for the experiments shown in c. A temporal average of the data points during the period of interest (the last 5 min) was used for the results and statistical comparison. (e) Schematic illustration showing cannula tip of the electrophysiological experiments shown in this figure. Left, vehicle-infused group (open circle). Right, LY34|495-infused group (filled circle).

weakening at C-LA synapses. Microinfusion of an mGluR2/3 antagonist, LY341495, into the LA during extinction training impairs extinction retention, although it did not change fear responses during extinction training (see Figure 2). In contrast, LY341495 infusion into the CeA, adjacent to the LA, during extinction training does not alter either fear responses during extinction training or extinction retention, suggesting that the effects of LY341495 infusion is limited to 
the LA. Furthermore, LY341495 infusion during extinction training also blocks a long-term weakening of presynaptic release probability at C-LA synapses, which results from extinction training, as evidenced by the results that LY341495 infusion into the LA blocks the extinctioninduced decrease in input-output relation and increase in PPR (see Figures 4 and 5). However, the same infusion during extinction training did not alter synaptic efficacy at other excitatory or inhibitory synapses in the LA, suggesting that LY341495 infusion specifically acts on C-LA synapses. These findings suggest that activation of $m G l u R 2 / 3$ is required for the long-term decrease in presynaptic release probability at C-LA synapses that supports extinction retention.

Although it is difficult to determine whether the LY341495 concentration used herein is specific only to $\mathrm{mGluR} 2 / 3$, in the present study, we provide some evidence suggesting that this is the case. It has been previously reported that distinct subtypes of mGluRs contribute to synaptic depression at T-LA and C-LA synapses in slices prepared from fearconditioned rats, respectively (Kim et al, 2007b; Hong et al, 2009). mGluR1/5 is involved in synaptic depression at T-LA synapses (Kim et al, 2007b), whereas mGluR2/3 is responsible for synaptic depression at C-LA synapses (Hong et al, 2009). These two forms of synaptic depression are known to be recruited during extinction training because extinction training occluded them all (Kim et al, 2007b; Hong et al, 2009). In another word, extinction training is likely to recruit the two forms of synaptic depression via activation of mGluR1/5 and 2/3, respectively. On the basis of these previous findings and logics, in the present study, we have examined whether the presence of LY341495 during extinction training disrupts the recruitment of C-LA or T-LA synaptic depression. If the dose of LY341495 is low enough to block mGluR2/3 specifically, LY341495 infusion with extinction training would disrupt the recruitment of mGluR2/3-dependent synaptic depression at C-LA synapses, but not that of mGluR1/5-dependent synaptic depression at T-LA synapses. Therefore, LY341495 infusion with extinction training is expected to impair the occlusive effect of extinction training on C-LA synaptic depression but not on T-LA synaptic depression. On the other hand, if the dose of LY341495 is high enough to inhibit all mGluR subtypes, the recruitment of both C-LA and T-LA synaptic depression would be disrupted, which impairs the occlusive effects of extinction training on the two forms of synaptic depression. In fact, we have found that LY341495 infusion with extinction training impairs the occlusive effect of extinction training on C-LA synaptic depression but not on T-LA synaptic depression (see Figure 6). These results suggest that the dose of LY341495 used herein is low enough to selectively inhibit mGluR2/3.

To reach a conclusive picture of C-LA modulation of the acquisition and extinction of conditioned fear via mGluR2/3, it needs to be elucidated which precise subtype (ie, mGluR2 or 3) is critical for fear conditioning and subsequent extinction. In this respect, it is worthwhile to note that a selective mGluR2 agonist, LY395756, is available (Ceolin et al, 2011; Lucas et al, 2013). Furthermore, a Wistar rat strain that does not express mGluR2 and/or mGluR2 KO mice will be useful for determining the mGluR subtypes that are involved in fear conditioning and extinction (Ceolin et al,
2011; Lucas et al, 2013). Indeed, a previous study has reported, using these pharmacological and genetic tools, that the activation of either mGluR2 or mGluR3 can induce a long-term depression at C-LA synapses (Lucas et al, 2013). Thus, it will be very interesting to identify the relative roles of mGluR2 and mGluR3 in fear conditioning and extinction, using mGluR2-deficient animals and the new pharmacological agents that can selectively distinguish between the two mGluR subtypes.

One distinct feature of the blockade of C-LA synaptic weakening using LY341495 is that only extinction retention (ie, extinction consolidation), but not fear responses during extinction training, is impaired by LY341495, a profile similar to the results previously obtained when the prefrontal cortex is silenced (Lebron et al, 2004). In fact, the selective impairment of extinction retention is considered a failure in the acquisition or consolidation of extinction memory during extinction training. Intriguingly, as shown in the present study, this phenotype is also apparent when the weakening of C-LA synaptic efficacy is impaired by LY341495 infusion. One possibility is that LTD itself at C-LA synapses encodes extinction memory, as shown in other examples (Ito, 1986; Cho et al, 2000; Griffiths et al, 2008; Ge et al, 2010); that is, blockade of C-LA LTD induction could lead to the failure in acquisition of extinction memory, thereby impairing extinction retention. Another possibility is that LTD at C-LA synapses shown herein represents a reversal (ie, a depotentiation) of conditioning-induced synaptic potentiation just as in the case of synaptic depotentiation at T-LA synapses. However, the latter hypothesis does not fit with the previous result that blockade of T-LA synaptic depotentiation blocks both extinction retention and fear responses during extinction training. To distinguish between these two possibilities, it should be elucidated whether synaptic depression at C-LA synapses after extinction training is expressed at naive synapses, potentiated synapses, or both.

Metabotropic glutamate receptors have been a molecular target for the development of new drugs, so a number of agonists and antagonists have been developed (Sanacora et al, 2008; Conn et al, 2009). The mGluR2/3 agonists may be good candidates for treating aberrant fear-related disorders such as flashbacking PTSD and phobia based on the findings in the present study and because the mGluR2/3 agonists are also known to display anxiolytic activity (Monn et al, 1997; Helton et al, 1998; Linden et al, 2005; Aujla et al, 2008). In fact, microinfusion of DCG-IV, an mGluR2/3 agonist, into the amygdala has been shown to quench conditioned fear, but this effect is quite limited such that DCG-IV is only effective when injected within $1 \mathrm{~h}$ after conditioning (Walker et al, 2002; Lin et al, 2005). To enhance the effectiveness of the quenching effect, it may be critical to determine a precise subtype of mGluRs for C-LA LTD and to develop a more specific agonist for each subtype (Ceolin et al, 2011; Lucas et al, 2013). Instead, chemical induction of C-LA LTD may require activation of additional molecular targets. In any case, further study of molecular mechanisms underlying C-LA LTD will contribute to the development of new drugs or treatments for fear/anxiety-related disorders. 


\section{FUNDING AND DISCLOSURE}

This work was supported by the NRF of Korea grant funded by the Korea government the Ministry of Education, Science and Technology (MEST) (No. 2011-0018209), by the Original Technology Research Program for Brain Science through the NRF of Korea funded by MEST (No. 20110019226), and by a grant from the Korea Health Technology R\&D Project through the Korea Health Industry Development Institute (KHIDI), funded by the Ministry of Health and Welfare, Republic of Korea (grant number: HI12C1492). JK, BA, and SP were supported by Brain Korea 21 Research Fellowships from the Korean Ministry of Education. The remaining authors declare no conflict of interest.

\section{REFERENCES}

Aujla H, Martin-Fardon R, Weiss F (2008). Rats with extended access to cocaine exhibit increased stress reactivity and sensitivity to the anxiolytic-like effects of the mGluR 2/3 agonist LY379268 during abstinence. Neuropsychopharmacology 33: 1818-1826.

Bouton ME, Kenney FA, Rosengard C (1990). State-dependent fear extinction with two benzodiazepine tranquilizers. Behav Neurosci 104: 44-55.

Ceolin L, Kantamneni S, Barker GR, Hanna L, Murray L, Warburton EC et al (2011). Study of novel selective mGlu2 agonist in the temporo-ammonic input to CA1 neurons reveals reduced $\mathrm{mGlu} 2$ receptor expression in a Wistar substrain with an anxiety-like phenotype. J Neurosci 31: 6721-6731.

Chi H, Jang JK, Kim JH, Vezina P (2006). Blockade of group II metabotropic glutamate receptors in the nucleus accumbens produces hyperlocomotion in rats previously exposed to amphetamine. Neuropharmacology 51: 986-992.

Cho K, Kemp N, Noel J, Aggleton JP, Brown MW, Bashir ZI (2000). A new form of long-term depression in the perirhinal cortex. Nat Neurosci 3: 150-156.

Conn PJ, Lindsley CW, Jones CK (2009). Activation of metabotropic glutamate receptors as a novel approach for the treatment of schizophrenia. Trends Pharmacol Sci 30: 25-31.

Dalton GL, Wang YT, Floresco SB, Phillips AG (2008). Disruption of AMPA receptor endocytosis impairs the extinction, but not acquisition of learned fear. Neuropsychopharmacology 33: 2416-2426.

Davis M, Myers KM, Chhatwal J, Ressler KJ (2006). Pharmacological treatments that facilitate extinction of fear: relevance to psychotherapy. NeuroRx 3: 82-96.

Ehrlich I, Humeau Y, Grenier F, Ciocchi S, Herry C, Luthi A (2009). Amygdala inhibitory circuits and the control of fear memory. Neuron 62: 757-771.

Fendt M, Schmid S, Thakker DR, Jacobson LH, Yamamoto R, Mitsukawa $\mathrm{K}$ et al (2008). mGluR7 facilitates extinction of aversive memories and controls amygdala plasticity. Mol Psychiatry 13: $970-979$.

Fontanez-Nuin DE, Santini E, Quirk GJ, Porter JT (2011). Memory for fear extinction requires mGluR5-mediated activation of infralimbic neurons. Cereb Cortex 21: 727-735.

Ge Y, Dong Z, Bagot RC, Howland JG, Phillips AG, Wong TP et al (2010). Hippocampal long-term depression is required for the consolidation of spatial memory. Proc Natl Acad Sci USA 107: 16697-16702.

Griffiths S, Scott H, Glover C, Bienemann A, Ghorbel MT, Uney J et al (2008). Expression of long-term depression underlies visual recognition memory. Neuron 58: 186-194.

Helton DR, Tizzano JP, Monn JA, Schoepp DD, Kallman MJ (1998). Anxiolytic and side-effect profile of LY354740: a potent, highly selective, orally active agonist for group II metabotropic glutamate receptors. J Pharmacol Exp Ther 284: 651-660.

Herry C, Ciocchi S, Senn V, Demmou L, Muller C, Luthi A (2008). Switching on and off fear by distinct neuronal circuits. Nature 454: 600-606.

Hong I, Song B, Lee S, Kim J, Kim J, Choi S (2009). Extinction of cued fear memory involves a distinct form of depotentiation at cortical input synapses onto the lateral amygdala. Eur J Neurosci 30: 2089-2099.

Ito $M$ (1986). Long-term depression as a memory process in the cerebellum. Neurosci Res 3: 531-539.

Kim J, Lee S, Park H, Song B, Hong I, Geum D et al (2007a). Blockade of amygdala metabotropic glutamate receptor subtype 1 impairs fear extinction. Biochem Biophys Res Commun 355: $188-193$.

Kim J, Lee S, Park K, Hong I, Song B, Son G et al (2007b). Amygdala depotentiation and fear extinction. Proc Natl Acad Sci USA 104: 20955-20960.

Kim J, Song B, Hong I, Kim J, Lee J, Park S et al (2010). Reactivation of fear memory renders consolidated amygdala synapses labile. J Neurosci 30: 9631-9640.

Lebron K, Milad MR, Quirk GJ (2004). Delayed recall of fear extinction in rats with lesions of ventral medial prefrontal cortex. Learn Mem 11: 544-548.

Likhtik E, Popa D, Apergis-Schoute J, Fidacaro GA, Pare D (2008). Amygdala intercalated neurons are required for expression of fear extinction. Nature 454: 642-645.

Lin CH, Lee CC, Huang YC, Wang SJ, Gean PW (2005). Activation of group II metabotropic glutamate receptors induces depotentiation in amygdala slices and reduces fear-potentiated startle in rats. Learn Mem 12: 130-137.

Linden AM, Bergeron M, Schoepp DD. (2005). Comparison of c-Fos induction in the brain by the $\mathrm{mGlu} 2 / 3$ receptor antagonist LY341495 and agonist LY354740: evidence for widespread endogenous tone at brain mGlu2/3 receptors in vivo. Neuropharmacology 49: 120-134.

Lodge D, Tidball P, Mercier MS, Lucas SJ, Hanna L, Ceolin L et al (2013). Antagonists reversibly reverse chemical LTD induced by group I, group II and group III metabotropic glutamate receptors. Neuropharmacology 74: 135-146.

Lucas SJ, Bortolotto ZA, Collingridge GL, Lodge D. (2013). Selective activation of either mGlu2 or mGlu3 receptors can induce LTD in the amygdala. Neuropharmacology 66: 196-201.

Mao SC, Chang CH, Wu CC, Orejarena MJ, Manzoni OJ, Gean PW. (2013). Inhibition of spontaneous recovery of fear by mGluR5 after prolonged extinction training. PLoS One 8: e59580.

Maren S (1999). Neurotoxic basolateral amygdala lesions impair learning and memory but not the performance of conditional fear in rats. J Neurosci 19: 8696-8703.

Maren S, Quirk GJ (2004). Neuronal signaling of fear memory. Nat Rev Neurosci 5: 844-852.

Milad MR, Quirk GJ (2002). Neurons in medial prefrontal cortex signal memory for fear extinction. Nature 420: 70-74.

Monn JA, Valli MJ, Massey SM, Wright RA, Salhoff CR, Johnson BG et al (1997). Design, synthesis, and pharmacological characterization of (+)-2-aminobicyclo[3.1.0] hexane-2,6-dicarboxylic acid (LY354740): a potent, selective, and orally active group 2 metabotropic glutamate receptor agonist possessing anticonvulsant and anxiolytic properties. J Med Chem 40: 528-537.

Myers KM, Davis M (2002). Behavioral and neural analysis of extinction. Neuron 36: 567-584.

Myers KM, Carlezon WA Jr., Davis M (2011). Glutamate receptors in extinction and extinction-based therapies for psychiatric illness. Neuropsychopharmacology 36: 274-293.

Pare D, Duvarci S (2012). Amygdala microcircuits mediating fear expression and extinction. Curr Opin Neurobiol 22: 717-723.

Quirk GJ, Armony JL, LeDoux JE (1997). Fear conditioning enhances different temporal components of tone-evoked spike 
trains in auditory cortex and lateral amygdala. Neuron 19: 613-624.

Rogan MT, Staubli UV, LeDoux JE (1997). Fear conditioning induces associative long-term potentiation in the amygdala. Nature 390: 604-607.

Royer S, Pare D (2002). Bidirectional synaptic plasticity in intercalated amygdala neurons and the extinction of conditioned fear responses. Neuroscience 115: 455-462.

Sah P, Lopez De Armentia M (2003). Excitatory synaptic transmission in the lateral and central amygdala. Ann N Y Acad Sci 985: 67-77.

Sakagami K, Yasuhara A, Chaki S, Yoshikawa R, Kawakita Y, Saito A et al (2008). Synthesis, in vitro pharmacology, and pharmacokinetic profiles of 2-[1-amino-1-carboxy-2-(9H-xanthen9-yl)-ethyl]-1-fluorocyclopropanecarboxylic acid and its 6-heptyl ester, a potent mGluR2 antagonist. Bioorg Med Chem 16: 4359-4366.

Sanacora G, Zarate CA, Krystal JH, Manji HK (2008). Targeting the glutamatergic system to develop novel, improved therapeutics for mood disorders. Nat Rev Drug Discov 7: 426-437.

Schroeder BW, Shinnick-Gallagher P (2005). Fear learning induces persistent facilitation of amygdala synaptic transmission. Eur $J$ Neurosci 22: 1775-1783.

Sepulveda-Orengo MT, Lopez AV, Soler-Cedeno O, Porter JT (2013). Fear extinction induces mGluR5-mediated synaptic and intrinsic plasticity in infralimbic neurons. J Neurosci 33 7184-7193.

Sethna F, Wang H. (2014). Pharmacological enhancement of mGluR5 facilitates contextual fear memory extinction. Learn Mem 21: 647-650.

Swanson CJ, Bures M, Johnson MP, Linden AM, Monn JA, Schoepp DD (2005). Metabotropic glutamate receptors as novel targets for anxiety and stress disorders. Nat Rev Drug Discov 4: 131-144.

Toth I, Dietz M, Peterlik D, Huber SE, Fendt M, Neumann ID et al (2012). Pharmacological interference with metabotropic glutamate receptor subtype 7 but not subtype 5 differentially affects within- and between-session extinction of Pavlovian conditioned fear. Neuropharmacology 62: 1619-1626.

Tsvetkov E, Carlezon WA, Benes FM, Kandel ER, Bolshakov VY (2002). Fear conditioning occludes LTP-induced presynaptic enhancement of synaptic transmission in the cortical pathway to the lateral amygdala. Neuron 34: 289-300.

Walker DL, Rattiner LM, Davis M. (2002). Group II metabotropic glutamate receptors within the amygdala regulate fear as assessed with potentiated startle in rats. Behav Neurosci 116: 1075-1083.

Zucker RS (1989). Short-term synaptic plasticity. Annu Rev Neurosci 12: 13-31. 